\title{
Tris(bis(trimethylsilyl)amido)samarium: X-ray Structure and DFT Study
}

Erik D. Brady, ${ }^{\mathrm{a}}$ David L. Clark, ${ }^{\mathrm{b}}$ John C. Gordon, ${ }^{\mathrm{a}}$ P. Jeffrey Hay*, c D. Webster Keogh*, Rinaldo Poli*d Brian L. Scott, ${ }^{\mathrm{a}}$ and John G. Watkin ${ }^{\mathrm{a}}$

${ }^{a}$ Chemistry Division, Los Alamos National Laboratory, Mail Stop J514, Los Alamos, NM 87545, USA.

${ }^{b}$ Nuclear Materials Technology Division and G. T. Seaborg Institute, Los Alamos National Laboratory, Mail Stop E500, Los Alamos, NM 87545, USA.

${ }^{c}$ Theoretical Division, Los Alamos National Laboratory, Mail Stop B268, Los Alamos, NM 87545, USA.

${ }^{d}$ Laboratoire de Synthèse et d'Electrosynthèse Organométalliques (LSEO UMR 5632), Université de Bourgogne, Faculté de Sciences "Gabriel”, 6 boulevard Gabriel, 21000 Dijon, France.

Proofs to:

D. Webster Keogh

Tel.: +1 5056657214

Fax: +1 5056657895

E-mail: wkeogh@lanl.gov 


\section{Abstract}

The compound $\mathrm{Sm}\left[\mathrm{N}\left(\mathrm{SiMe}_{3}\right)_{2}\right]_{3}$ has been investigated experimentally by X-ray crystallography and computationally by DFT methods. The structure is analogous to that of other tris[bis(trimethylsilyl)amido]lanthanides, featuring positional disorder of the metal atom above and below the plane defined by the the three $\mathrm{N}$ donor atoms, resulting in a trigonal pyramidal configuration. One of the methyl groups of each amido ligand is placed above the apex of the pyramid at close distance to the metal center suggesting the presence of agostic interactions. The DFT calculations have been carried out on the real molecule and on a $\mathrm{Si}\left[\mathrm{N}\left(\mathrm{SiH}_{3}\right)\left(\mathrm{SiH}_{2} \mathrm{Me}\right)\right]_{3}$ model where the unique Me group was placed above the apex of the pyramid to probe the agnostic agostic interaction. In both cases, the optimized geometry reproduces very well the experimental structure and indicates the presence of $\beta$-Si-C agostic interactions. A comparison of the optimized geometries obtained in the presence/absence of the Sm $d$ and the Si $d$ orbitals serves to illustrate the relevance of these orbitals for $(i)$ the establishment of the pyramidal configuration at Sm; (ii) the Sm-N bond length; and (iii) the Sm( $\beta$-Si-C) bond length. The bonding analysis, which was carried out by both Mulliken and NBO methods, confirms the importance of the metal $d$ orbitals for the Sm-N and Sm- $(\beta-\mathrm{Si}-\mathrm{C})$ chemical bonding but also illustrates the relevance of electrostatic terms in the agostic interaction. Sm-N and N-Si $\pi$ bonding is present according to the bonding analysis but is not important for enforcing the planar configuration at $\mathrm{N}$, nor the pyramidal configuration at Sm. 


\section{Introduction}

The bis(trimethylsilyl)amido ligand has been extensively used in lanthanide chemistry, as well as in actinide and transition metal chemistry, to stabilize electronically unsaturated metal centers due to the combination of its steric encumbrance and the available lone pair on the nitrogen donor atom for additional $\pi$-bonding interactions. Among the lanthanide metals, homoleptic trivalent and divalent complexes of type $\left\{\mathrm{Ln}\left[\mathrm{N}\left(\mathrm{SiMe}_{3}\right)_{2}\right]_{3}\right\}^{\mathrm{n}-}[\mathrm{n}=0$ for $\mathrm{Ln}(\mathrm{III}), 1$ for $\operatorname{Ln}(\mathrm{II})]$ have been structurally characterized either in the solid state or in the gas phase for $\mathrm{Ce}(\mathrm{III}),{ }^{1,2} \mathrm{Pr}(\mathrm{III}),{ }^{1} \mathrm{Nd}(\mathrm{III}),{ }^{3} \mathrm{Eu}(\mathrm{II}),{ }^{4} \mathrm{Eu}(\mathrm{III}),{ }^{5} \mathrm{Dy}(\mathrm{III}),{ }^{6} \mathrm{Er}(\mathrm{III}),{ }^{6} \mathrm{Yb}(\mathrm{II}),{ }^{4}$ and $\mathrm{Yb}(\mathrm{III}) .{ }^{7}$ One feature that appears unique for this series of homoleptic lanthanide complexes and for the analogous $\mathrm{Sc}(\mathrm{III})$ (only in the solid state) ${ }^{5}$ and $\mathrm{U}$ (III) derivatives ${ }^{8}$ is the pyramidal arrangement of the central $\mathrm{MN}_{3}$ core. In single crystal studies, the metal atom is unfailingly found disordered between two equivalent positions above and below the plane of the three $\mathrm{N}$ donor atoms. The $\mathrm{Si}$ $\mathrm{N}-\mathrm{Si}$ plane for each ligand is tilted relative to the normal to the $\mathrm{N}_{3}$ plane, establishing a $\mathrm{D}_{3}$ "propeller" arrangement of the three $\mathrm{N}\left(\mathrm{SiMe}_{3}\right)_{2}$ ligands. Transition metal complexes with the same stoichiometry, on the other hand, display a trigonal planar geometry. ${ }^{7,9,10}$

Recently, models of the lanthanide $\mathrm{M}\left[\mathrm{N}\left(\mathrm{SiMe}_{3}\right)_{2}\right]_{3}$ complexes have been subjected to DFT studies by Eisenstein and coworkers. ${ }^{11,12}$ A study on $\mathrm{M}\left(\mathrm{NR}_{2}\right)_{3}$ with $\mathrm{R}=\mathrm{H}$ has accurately reproduced the Ln-N distances across the lanthanide series and has shown that the participation of the $4 f$ shell to the bonding can be neglected. ${ }^{11}$ However, they found that the optimized geometries are planar ( $\mathrm{N}-\mathrm{Ln}-\mathrm{N}$ angles close to $120^{\circ}$ ), in disagreement with the data found experimentally. A related study with $\mathrm{R}=\mathrm{SiH}_{3}$ yields $\mathrm{Ln}-\mathrm{N}$ distances in better agreement with the

experimental values relative to the $\mathrm{R}=\mathrm{H}$ case, ${ }^{12}$ but the coordination geometry around the 
lanthanide metal is again trigonal planar when no polarization functions are added to the silicon atoms. The addition of $d$ functions to the Si basis set, however, besides yielding an even better agreement for the Ln-N distances, provides two stable minima on the potential energy surface. The higher energy minimum corresponds to the incorrect trigonal planar structure previously alluded to; the more stable minimum yields the qualitatively correct pyramidal structures and displays three $\beta$-Si-H agostic interactions with one $\mathrm{SiH}_{3}$ group of each amido ligand. ${ }^{12}$ While the pyramidal distortion is not quantitatively analyzed in this contribution, the driving force for this pyramidalization is attributed to the establishment of agostic interactions.

More recently, we ${ }^{13}$ and Maron and Eisenstein ${ }^{14}$ have carried out independent computational analyses of the related $\mathrm{Ln}\left[\mathrm{CH}\left(\mathrm{SiMe}_{3}\right)_{2}\right]_{3}$ complexes that were synthesized and structurally characterized by Lappert, Power et al. in 1988 for $\mathrm{Ln}=\mathrm{La}$ and $\mathrm{Sm} .{ }^{15}$ These complexes also display a pyramidalized $\mathrm{LnC}_{3}$ coordination geometry. DFT calculations were carried out on $\mathrm{Ln}\left[\mathrm{CH}\left(\mathrm{SiR}_{2} \mathrm{R}^{\prime}\right)\left(\mathrm{SiR}_{3}\right)\right]_{3}$ for (i) $\mathrm{R}=\mathrm{R}^{\prime}=\mathrm{Me}$, (ii) $\mathrm{R}=\mathrm{H}, \mathrm{R}^{\prime}=\mathrm{Me}$, and (iii) $\mathrm{R}=\mathrm{R}^{\prime}$ $=\mathrm{H}$ as well as on simpler models. ${ }^{13,14}$ In summary, both systems (i) and (ii) correctly reproduced the molecular geometry, including the degree of pyramidalization. The coordination geometry is enforced by $\beta$-Si-C interactions, whereas the interactions between the metal center and the $\gamma-\mathrm{C}-\mathrm{H}$ bonds are repulsive. Finally, the simpler models (iii) yield qualitatively correct pyramidal geometries but the stronger $\beta-\mathrm{Si}-\mathrm{H}$ agostic interactions introduce important quantitative differences. The driving force for the adoption of the pyramidal structure has been attributed to a $2^{\text {nd }}$ order Jahn-Teller (JT) effect and an inversion barrier that is extremely small. ${ }^{14}$

In view of the above investigations, it seemed likely that the factors enforcing the pyramidal structure for the triamido derivatives could be the same as for the trialkyl compounds and that a more accurate model than the previously used $\mathrm{N}\left(\mathrm{SiH}_{3}\right)_{2}$ ligand was necessary. As part 
of our study, we have also synthesized the already known ${ }^{16} \mathrm{Sm}(\mathrm{III})$ member of the tris[bis(trimethylsilyl)amido]lanthanide family. Since the solid state structure of this compound was not yet available in the literature, we have determined it and are reporting it here together with the computational study.

\section{Experimental}

X-ray Crystallography of $\mathrm{Sm}\left[\mathbf{N}\left(\mathrm{SiMe}_{3}\right)_{2}\right]_{3} \cdot \mathbf{2 C}_{6} \mathbf{H}_{14} \cdot$ Compound $\mathrm{Sm}\left[\mathrm{N}\left(\mathrm{SiMe}_{3}\right)_{2}\right]_{3}$ was prepared as previously described by Bradley and coworkers. ${ }^{16}$ Colorless crystals were grown by slow evaporation of a saturated hexanes solution at room temperature. The crystals were transferred to a Petri dish filled with a small amount of light mineral oil. A suitable crystal was chosen by examination under a microscope and was attached to a glass fiber using silicone grease, followed by mounting on a Bruker P4/CCD/PC diffractometer for data collection at 203 K. Data collection and structure solution were conducted at Los Alamos National Laboratory. All calculations were performed using the SHELXTL V5.10 suite of programs. ${ }^{17}$ Final cell constants were calculated from a set of strong reflections measured during the actual data collection. Relevant crystal and data collection parameters are given in Table 1.

$<$ Table 1>

The space group $P 3,{ }^{-} 1 c$ was determined from systematic absences and intensity statistics. The initial direct-methods solution revealed all of the non-hydrogen atom positions. All nonhydrogen atoms were refined with anisotropic displacement parameters. The Sm atom was 
refined in two one-half occupancy positions due to disorder of the molecule on a site of $\left(D_{3}\right)$ symmetry. A severely disordered n-hexane molecule was found in the lattice on a site of threefold rotation symmetry. Attempts to model the lattice n-hexane were unsuccessful, and the program PLATON/SQUEEZE ${ }^{18}$ was used to remove the $n$-hexane solvent density. All $\mathrm{H}$ atoms were placed in ideal positions $(\mathrm{C}-\mathrm{H}=0.96 \AA)$ and refined as riding atoms with isotropic temperature factors set at 1.5 times the equivalent isotropic $U$ of the $\mathrm{C}$ atom to which they were bound. Absorption corrections were performed with the program SADABS. ${ }^{19}$

Computational Details All calculations were carried out using the $\mathrm{B}^{2} \mathrm{LYP}^{20}$ functional and employing "large-core" relativistic effective core potentials (RECPs) ${ }^{21,22}$ on the Sm atom. The $\left[\ldots 4 s^{2} 4 p^{6} 4 d^{10} 4 f^{5}\right]$ core electrons of the Sm including the partially occupied $4 \mathrm{f}$ shell are replaced by the RECP leaving the $5 s^{2} 5 p^{6} 6 s^{2} 5 d^{1}$ electrons treated explicitly as valence electrons. A contracted [5s $4 \mathrm{p} 3 \mathrm{~d}$ ] basis is employed except where noted below for Sm. The 6-31G basis forms the starting point for the ligands. All calculations were carried out with Gaussian98 ${ }^{23}$ without symmetry constraints $\left(\mathrm{C}_{1}\right.$ symmetry $)$.

Three basis sets were employed for the calculations. The smallest one (denoted 6-31G) is comprised of the above contracted basis for Sm and 6-31G for C, N, Si and H. A second basis set (denoted 6-31G**) adds polarization on all $\mathrm{H}(p), \mathrm{C}(d)$, and $\mathrm{Si}(d)$ atoms. A third basis set is identical with the 6-31G basis set except that no $d$ functions were used for the Sm atom. In the discussion on van der Waals radii, standard radii $^{24}$ were taken for $\mathrm{C}\left(\begin{array}{lll}1.70 & \AA\end{array}\right)$ and $\mathrm{Si}(2.10 \AA)$. The Sm values were obtained from the measured covalent radius in the corresponding trialkyl complex $\mathrm{Sm}\left[\mathrm{CH}\left(\mathrm{SiMe}_{3}\right)_{2}\right]_{3}{ }^{13,14}$ and using the relation ${ }^{25} \mathrm{R}_{\mathrm{vdW}}=\mathrm{R}_{\mathrm{cov}}+0.80 \AA$, the $\mathrm{Sm}-\mathrm{C}(2.33 \AA)$ bond length, and $\mathrm{R}_{\mathrm{cov}}=0.77 \AA$ for $\mathrm{C}$. This yields a van der Waals radius of $2.36 \AA$. 
A standard Mulliken population analysis was carried out to obtain total atomic populations and charges, and atomic contributions were also determined for selected individual molecular orbitals. For comparison, total atomic charges were also determined using natural bond orbital (NBO) analysis. In using Gaussian98 for Sm with partially occupied 4f orbitals incorporated into the RECP, two modifications were made after the final SCF calculation before performing the NBO analysis. An extra "dummy" $f$ basis function (with exponent 1000) was added to the $\mathrm{Sm}$ basis, and the atomic number of Sm was replaced by that of La.

\section{Results and Discussion}

(a) X-ray rystal Structure of $\mathrm{Sm}\left[\mathrm{N}\left(\mathrm{SiMe}_{3}\right)_{2}\right]_{3}$.

A thermal ellipsoid view of the molecular geometry of $\mathrm{Sm}\left[\mathrm{N}\left(\mathrm{SiMe}_{3}\right)_{2}\right]_{3}$ is shown in Figure 1 and selected bond lengths and angles are given in Table 2. The molecular geometry consists of one Sm atom and three bis(trimethylsilyl)amido ligands arranged in a trigonal pyramidal fashion. In addition, one $\mathrm{C}$ atom $(\mathrm{C} 1)$ on each amido ligand displays a close contact (3.003(4) $\AA$ ) with the metal center, affording an effective pseudo trigonal prismatic geometry about the Sm center. This structural motif is identical to the other structurally authenticated tris[bis(trimethylsilyl)amido] complexes of the lanthanides, including those of $\mathrm{Nd},{ }^{3} \mathrm{Eu},{ }^{5} \mathrm{Dy},{ }^{6}$ $\mathrm{Er},{ }^{6}$ and $\mathrm{Yb}^{7}{ }^{7}$ which have non-planar, pyramidal structures that crystallize in the $P 3,{ }^{-} 1 c$ space

group. Also identical to the other triamido lanthanide compounds is the planar configuration of the $\mathrm{N}$ atoms (the sum the of angles at $\mathrm{N}$ is $359.4(2)^{\circ}$ ).

$<$ Figure 1 and Table 2> 
As might be predicted, the Ln-N bond length decreases across the series as the radius of the Ln metal center decreases. The Sm derivative has a Ln-N bond length of 2.284(5) $\AA$, which falls between that of $\mathrm{Nd}(2.29(2) \AA)$ and $\mathrm{Eu}(2.259(9) \AA)$. It appears that a significant amount of coordinative unsaturation is satisfied by the formation of close intramolecular contacts, as none of the reported structures have coordinated solvent. All of the tris[bis(trimethylsilyl)amido] lanthanides possess these close $\mathrm{Ln}-\mathrm{C}$ contacts suggesting to us that this family of compounds may be most appropriately described as pseudo six-coordinate..$^{3,5}$

\section{(b) Calculations on the Real Molecule}

DFT computational studies have been carried out on two molecules, namely $\mathrm{Sm}\left[\mathrm{N}\left(\mathrm{SiR}_{2} \mathrm{Me}\right)\left(\mathrm{SiR}_{3}\right)\right]_{3}$ with $\mathrm{R}=\mathrm{CH}_{3}$ and $\mathrm{H}$, by using the B3LYP functional. The model with $\mathrm{R}$ $=\mathrm{H}$ was generated by replacing all methyl groups in the real molecule with $\mathrm{H}$ atoms, except for the methyl group closest to the metal center. A general drawing of the interaction between the metal and a single alkyl substituent is shown in Scheme 1. All relevant geometrical results are collected in Table 2 and views of the optimized geometries are shown in Figure 2.

$<$ Scheme 1 and Figure $2>$

The geometry of the full molecule was optimized with a small basis set (6-31G) only. Furthermore, this calculation (as well as all the others reported in this paper) was carried out with a large core which included also the $4 \mathrm{f}$ electrons. Our previous comparative study on the $\mathrm{Sm}\left[\mathrm{CH}\left(\mathrm{SiR}_{2} \mathrm{Me}\right)\left(\mathrm{SiR}_{3}\right)\right]_{3}$ system has shown that the explicit consideration of the $4 \mathrm{f}$ electrons in the valence shell, while rendering the calculation much more unstable and time consuming, did 
not lead to any significant improvement in quality. Although no polarization functions were used for any of the atoms, the calculated geometry reproduces the experimental pyramidal geometry quite well, with computed N-Ln-N angles of $116.3^{\circ}$ essentially identical to the values found experimentally $\left[115.52(2)^{\circ}\right]$. It is worth noting that the pyramidalization is less pronounced relative to the related $\mathrm{Sm}\left[\mathrm{CH}\left(\mathrm{SiMe}_{3}\right)_{2}\right]_{3}$, for which the calculated and experimental C-Sm-C angles are around $110^{\circ} .{ }^{13}$ The essentially planar configuration at $\mathrm{N}$ (sum of bond angles $=359.8^{\circ}$ ) is also in accord with the experiment. All bond distances are slightly longer than the experimental ones, as usually found at this level of theory, and the largest discrepancy between calculated and experimental bond angles is $c a .3^{\circ}$. The relatively poor fit of the N-Si and Si-C distances is largely due to the absence of polarization functions for this calculations (vide infra).

One Si-Me bond of each amido ligand (facing the metal from the apex side of the $\mathrm{LnN}_{3}$ pyramid and containing the silicon atom labeled as Si in Figure 2), is found in relatively close proximity to the metal center, as it does in the experimental structure, suggesting the existence of electronic (agostic) interactions. The other $\mathrm{SiMe}_{3}$ arm (with the silicon atom labeled as Si' in Figure 2), on the other hand, is farther away from the metal. The presence of agostic interactions is strongly suggested by several structural features. The most notable one is the more acute Ln$\mathrm{N}-\mathrm{Si}$ angle relative to the $\mathrm{Ln}-\mathrm{C}-\mathrm{Si}$ ' angles and also relative to the ideal $120^{\circ}$ value. The second one is the $\mathrm{Si}-\mathrm{CH}_{3}(\cdots \mathrm{Sm})$ distance (namely, the distance to the methyl group closest to the metal center), which is significantly longer then all the other $\mathrm{Si}-\mathrm{CH}_{3}$ distances. These two features are clear indications of an electronic interaction between the metal center and the $\beta$-Si-C bond. Additional indications are the relatively short $\mathrm{Sm} \cdots \mathrm{Si}$ and $\mathrm{Sm} \cdots \mathrm{C}$ contacts, i.e. significantly shorter than the sums of the van der Waal radii (4.46 and $4.06 \AA$, respectively). These contacts are even shorter than those in the previously analyzed $\mathrm{Sm}\left[\mathrm{CH}\left(\mathrm{SiMe}_{3}\right)_{2}\right]_{3}$ molecule. $^{13}$ 
The close $\mathrm{Ln} \cdots \mathrm{H}$ distances suggest the possible presence of additional agostic interactions with the $\gamma-\mathrm{C}-\mathrm{H}$ electron density, see Scheme 1. While the accurate position of the $\mathrm{H}$ atoms is not available from the X-ray study, the computational results provide strong indications against the presence of these interactions. Rather, the $\mathrm{Sm} \cdots(\mathrm{H}-\mathrm{C})$ interaction appears to be repulsive in nature. The first indication is the nearly staggered orientation, with respect to the $\mathrm{Sm} \cdots \mathrm{Si}$ axis, adopted by the $\mathrm{CH}_{3}$ fragments closest to the metal center (dihedral Sm $\cdots \mathrm{Si}-\mathrm{C}-\mathrm{H}$ angles in the proximity of $\pm 60^{\circ}$ ). The attractive interaction with the $\beta$-Si-C bonds, on the other hand, places the interacting methyl group at a Sm-N-Si-C dihedral angle near zero. The second one is the tilting of the Me group away from the metal ( $\mathrm{Si}-\mathrm{C}-\mathrm{H}$ angles are greater than the tetrahedral value for the two $\mathrm{H}$ atoms closest to the metal and smaller for the third $\mathrm{H}$ atom). The same situation is evident from the DFT results obtained for compounds $\mathrm{Ln}\left[\mathrm{CH}\left(\mathrm{SiMe}_{3}\right)_{2}\right]_{3}(\mathrm{Ln}=$ $\mathrm{La}, \mathrm{Sm})^{13,14}$ and $\left(\mathrm{C}_{5} \mathrm{H}_{5}\right) \mathrm{La}\left[\mathrm{CH}\left(\mathrm{SiMe}_{3}\right)_{2}\right]_{2} \cdot{ }^{26}$ The marginally longer $\mathrm{C}-\mathrm{H}$ distances for the two C-H bonds closest to the Ln center may be attributed to the carbon rehybridization caused by the distortion and, therefore, does not constitute indication for the presence of $\gamma$-C-H agostic interactions. $^{13}$

It is now useful to briefly compare the structural features of the title compound with those of the related trialkyl compound, $\mathrm{Sm}\left[\mathrm{CH}\left(\mathrm{SiMe}_{3}\right)_{2}\right]_{3}$. The agostic contact between the $\mathrm{Sm}$ center and the $\beta$-Si-C groups is shorter in the triamido compound relative to the related trialkyl compound where the $\mathrm{N}$ donor is replaced by $\mathrm{CH}$ (3.38 vs. $3.54 \AA)$. This shortening may simply be the consequence of the shorter Sm-N (ca. $2.30 \AA$ ) relative to the Sm-C bond in the trialkyl compound (ca. $2.45 \AA$ ). ${ }^{13}$ In spite of the formal $\mathrm{sp}^{2}$ hybridization at $\mathrm{N}$, the ideal $120^{\circ}$ angle is lowered to $107.6^{\circ}$ (calc. $111.0-113.2^{\circ}$ depending on the model and the basis set employed), vs. the $\mathrm{sp}^{3}$ hybridization at carbon, where the ideal $109.5^{\circ}$ angle is lowered to $106.6(12)^{\circ}$ (calc. 
103.9-104.6 $6^{\circ}$. The degree of pyramidalization, on the other hand, is more pronounced in the trialkyl compound $\left(\mathrm{C}-\mathrm{Sm}-\mathrm{C}=110^{\circ}\right.$ vs. $\mathrm{N}-\mathrm{Sm}-\mathrm{N}=116^{\circ}$ by both experiment and theory for the real molecule).

\section{(c) Calculations on the $\mathrm{Sm}\left[\mathrm{N}\left(\mathrm{SiH}_{3}\right)\left(\mathrm{SiH}_{2} \mathrm{Me}\right)\right]_{3}$ Model System.}

The data in Table 2 and a comparison of parts (a) and (b) of Figure 2 illustrate the validity of the chosen model to represent the metal-ligand interactions. All optimized parameters obtained at the 6-31G level are very close with those obtained for the real molecule at the same level of theory. The largest difference, i.e. the increase of the pyramidalization degree (the NSm-N angles decrease on average from 116.3 to 112.5 ), may be attributed to the release of steric pressure upon replacing the bulky $\mathrm{SiMe}_{3}$ groups in the real molecule with the smaller $\mathrm{SiH}_{3}$ groups. An analogous (though less pronounced, i.e. a $2^{\circ}$ decrease) phenomenon occurs when going from the related trialkyl $\mathrm{Ln}\left[\mathrm{CH}\left(\mathrm{SiMe}_{3}\right)_{2}\right]_{3}$ system to the $\mathrm{Ln}\left[\mathrm{CH}\left(\mathrm{SiH}_{3}\right)\left(\mathrm{SiH}_{2} \mathrm{Me}\right)\right]_{3}$ model.

In order to probe the effect of the basis set, a calculation was repeated for this simpler model by adding polarization functions on all $\mathrm{H}(p), \mathrm{C}(d)$, and $\mathrm{Si}(d)$ atoms (see results in Table 2). The essential features of the optimized structure do not change, remaining faithful to the experimental geometry. However, some parameters significantly improve, especially the distances involving the silicon atoms. The $\mathrm{Sm} \cdots \mathrm{Si}$ and $\mathrm{Sm} \cdots \mathrm{C}$ contacts are significantly shorter and closer to the experimental values in the presence of the polarization functions. As already found for the simple $\mathrm{Sm}\left[\mathrm{N}\left(\mathrm{SiH}_{3}\right)_{2}\right]_{3}$ system, ${ }^{12}$ the addition of the $d$ functions on Si shortens the $\mathrm{N}-\mathrm{Si}$ bonds and correspondingly slightly lengthens the Sm-N bonds. This phenomenon could possibly be attributed to the competition of $\mathrm{Si}$ and $\mathrm{Sm}$ for the $\mathrm{N}$ lone pairs (see section d). 
Our previous study on the $\mathrm{Sm}\left[\mathrm{CH}\left(\mathrm{SiR}_{2} \mathrm{R}^{\prime}\right)\left(\mathrm{SiR}_{3}\right)\right]_{3}\left(\mathrm{R}, \mathrm{R}^{\prime}=\mathrm{Me}, \mathrm{Me} ; \mathrm{H}, \mathrm{Me} ; \mathrm{H}, \mathrm{H}\right)$ systems had suggested that the $\mathrm{Sm} \cdots(\beta-\mathrm{Si}-\mathrm{H})$ interaction is stronger than the $\mathrm{Sm} \cdots(\beta-\mathrm{Si}-\mathrm{C})$ interaction by a simple comparison of structural parameters. Thus, we wondered whether a structural isomer of the present $\mathrm{Sm}\left[\mathrm{N}\left(\mathrm{SiH}_{3}\right)\left(\mathrm{SiH}_{2} \mathrm{Me}\right)\right]_{3}$ model where the $\mathrm{SiH}_{3}$ and $\mathrm{SiH}_{2} \mathrm{Me}$ groups had exchanged places would lead to a more stable structure. This is indeed the case, the resulting optimized geometry (shown in Figure 2c) being $2.8 \mathrm{kcal} / \mathrm{mol}$ more stable than the isomer of Figure $2 \mathrm{~b}$. The stronger agostic interaction with the $\mathrm{Si}-\mathrm{H}$ bond is confirmed by the shorter Sm..Si distance and by the more severely distorted Sm-N-Si angle (see Table 2). This result, though expected, is relevant because it gives a quantitative evaluation of the energy difference between the $\mathrm{Si}-\mathrm{H}$ and $\mathrm{Si}-\mathrm{C}$ agostic interactions $(0.9 \mathrm{kcal} / \mathrm{mol}$ per interaction $)$. This is close to the difference of $2.2 \mathrm{kcal} / \mathrm{mol}$ which was estimated by Maron, Eisenstein et al. on the basis of the activation barriers for making/breaking these interactions. ${ }^{14}$ Of course, this new isomer has no relevance to the experimental structure. It is interesting, however, to note that the degree of pyramidalization at the Sm atom (see Table 2) is nearly identical for the two isomers. As mentioned in the introduction, the use of the $\mathrm{N}\left(\mathrm{SiH}_{3}\right)_{2}$ model ligand in a previous study had proven unsatisfactory, ${ }^{12}$ giving rise to the wrong planar structure when no polarization functions were added to the Si atoms. Only in the presence of $d$ functions on the $\mathrm{Si}$ atoms did a pyramidal geometry correspond to the global minimum. The results presented here, however, feature a pyramidal $\mathrm{Sm}$ atom interacting with a $\beta-\mathrm{Si}-\mathrm{H}$ bond even in the absence of $d$ functions on the silicon atom. It is not clear how the addition of a methyl group to a non-interacting silyl substituent could influence this geometrical parameter. Either way, the results suggest that the $\beta$ Si-X agostic interaction $\left(\mathrm{X}=\mathrm{H}\right.$ or $\left.\mathrm{CH}_{3}\right)$ is essential to enforce the pyramidal geometry in this case. In this respect, we should note that the simple $\mathrm{La}\left(\mathrm{CH}_{3}\right)_{3}$ model, where no $\beta$-agostic 
interaction can be established, also adopts a pyramidal geometry according to DFT computations, ${ }^{14}$ whereas $\mathrm{La}\left(\mathrm{NH}_{2}\right)_{2}$ adopts a planar structure at the same level of theory. ${ }^{11}$ The preference of the trialkyl complex for a pyramidal geometry has been attributed to a second order Jahn-Teller effect, ${ }^{14}$ thus the question arises as to why the same effect would not be operative for the $\mathrm{La}\left(\mathrm{NH}_{2}\right)_{3}$ compound. Our discussion might provide a possible answer to this question (vide infra).

A final calculation on this model system was carried out without the Sm valence shell $d$ functions, in order to evaluate the importance of these orbitals for the establishment of the agostic interactions and other geometric features ( $\pi$-bonding, 2 nd order JT distortion, etc.). It may be expected that the establishment of as many as three agostic interactions should not be possible when the metal has only one $s$ and three $p$ functions available in the valence shell. Neither Sm-N $\pi$ bonding nor a 2nd order JT effect should be possible without $d$ orbitals on the lanthanide center. The latter interaction, in fact, is due to mixing of the filled $\sigma$-bonding Sm-N orbitals $(a+e)$ in $\mathrm{C}_{3}$ symmetry with the empty $\mathrm{Sm} d$ orbitals $(a+2 e)$. The result of this geometry optimization, starting from the optimized $\mathrm{R}=\mathrm{H}$ structure at the $6-31 \mathrm{G}$ level, unexpectedly led to a geometry which is closer to that of the more stable isomer. In other words, the three $\mathrm{Sm} \cdots(\mathrm{Si}-$ C) interactions are lost and the three new $\mathrm{Sm} \cdots(\mathrm{Si}-\mathrm{H})$ interactions with the $\mathrm{SiH}_{3}$ groups are established. This result indicates that the $d$ functions are important for defining a local minimum for the less stable $\beta$-Si-C agostic $\mathrm{Sm}\left[\mathrm{CH}\left(\mathrm{SiH}_{2} \mathrm{Me}\right)\left(\mathrm{SiH}_{3}\right)\right]_{3}$ isomer and confirm once again the greater affinity for the $\beta-\mathrm{Si}-\mathrm{H}$ agostic interaction. At any rate, we can still meaningfully compare this newly optimized structure with that of the stable $\beta-\mathrm{Si}-\mathrm{H}$ isomer at the $6-31 \mathrm{G}$ level (Table 2). 
The most important changes are as follows: $(i)$ the Sm-N distance becomes significantly longer (by ca. $0.07 \AA$ ); (ii) the $\mathrm{Sm} \cdots \mathrm{Si}$ and $\mathrm{Sm} \cdots \mathrm{H}$ interaction interactions lengthen considerably

(by 0.18 and $0.26 \AA$, respectively); (iii) the Sm coordination geometry becomes essentially planar. However, a significant agostic interaction remains, as clearly indicated by the persistence of a marked inequivalence of the Sm-N-Si and Sm-N-Si' angles.

\section{(d) Discussion of the Electronic Structure}

The bonding analysis that we have previously carried out for the corresponding trialkyl compounds, ${ }^{13}$ which was performed only at the Mulliken level, has highlighted the contribution of the metal $d$ orbitals to the Sm-C $\sigma$ bonding orbitals and has emphasized the role of covalent interactions, notably the agostic ones, for the stabilization of the molecule. Of course, there is no possibility for $\pi$ bonding in that case. In an independent study that paralleled ours and which was limited to the lanthanum compound, Perrin, Maron, Eisenstein and Lappert (PMEL) emphasized the role of ionic bonding on the basis of an NBO analysis. According to this analysis, the agostic interaction would be essentially electrostatic in nature and would result from a polarization of the electron density within the ligand skeleton by the highly electropositive metal, via negative hyperconjugation. The calculated natural charge of the lanthanide center in the related $\mathrm{Ln}\left(\mathrm{NH}_{2}\right)_{3}$ molecules is around +2.5 , consistent with an almost pure ionic bond. ${ }^{11}$ These authors also found no bonding critical point between the $\mathrm{La}$ and the $\beta$-Si-C electron density by an analysis of the Laplacian. On the other hand, they also discussed the role of the $d$ orbitals in enforcing the pyramidal distortion (2nd order JT effect). ${ }^{14}$

The title molecule will be analyzed from the points of view of the Mulliken and NBO analysis. While both methods provide an internally consistent description, the Mulliken analysis 
of bonding can overemphasize covalency or can sometimes yield nonphysical populations. The NBO analysis provides an alternate physical picture which has proven especially useful in cases of molecules featuring weak bonding interactions. ${ }^{27} \quad$ A quantitative assessment of the relative contribution of covalency and ionicity is not trivial, with both Mulliken and NBO views having their own merits. Our analysis, with less particular emphasis on the computed parameters such as charges and atomic orbital contributions, will focus on the qualitative trends of these parameters and especially on the structural changes resulting from the "computational experiments" of altering the basis functions available for bonding. This analysis will clearly show that both covalent and ionic contributions play an important role for determining the molecular structure.

The observed and calculated structural changes on going from the trialkyl to the triamido compound, on the one hand, and the effect of removing the samarium $d$ orbitals from the electronic structural calculation of the more stable $\mathrm{Sm}\left[\left(\mathrm{SiH}_{3}\right)\left(\mathrm{SiH}_{2} \mathrm{Me}\right)\right]_{3}$ isomer, on the other hand, demonstrate the relevant role that the $d$ orbitals play for establishing ( $i$ ) the pyramidal configuration at the metal center, (ii) the bonding to the nitrogen donor ( $\sigma$ and possibly also $\pi$ interactions) and (iii) the agostic interactions with the $\beta$-Si-C moieties. Interestingly, they do not seem important for enforcing the nitrogen atom planarity. We shall address these four effects one at a time and in that order.

Degree of pyramidalization. As discussed by PMEL for the related $\mathrm{La}\left[\mathrm{CH}\left(\mathrm{SiMe}_{3}\right)_{2}\right]_{3}$ compounds and models thereof, the metal $d$ orbital participation (notably the $e$-symmetrical $\mathrm{d}_{\mathrm{xz}}$ and $\mathrm{d}_{\mathrm{yz}}$ orbitals) provides hybrids that maximize overlap in a trigonal pyramidal configuration. ${ }^{14}$ The better the energy match, the greater the $d$ character, and the greater the bending away from planarity. This is the simple way in which one can understand the observed (and calculated) 
greater degree of pyramidalization for the compound with the less electronegative alkyl ligand (C-Ln-C $=$ ca. $110^{\circ}$ for both $\mathrm{La}$ and $\mathrm{Sm}$ trialkyl compounds) than that with the more electronegative amido ligand $\left(\mathrm{N}-\mathrm{Sm}-\mathrm{N}=\mathrm{ca} .116^{\circ}\right.$ for the triamido compound). Although there is steric repulsion affecting these angles, the same trend is observed for the less sterically hindered, and simpler $\mathrm{Ln}\left[\mathrm{E}\left(\mathrm{SiH}_{3}\right)\left(\mathrm{SiH}_{2} \mathrm{Me}\right)\right]_{3}$ models $\left(\mathrm{E}=\mathrm{CH}\right.$ : $105^{\circ}$ for $\mathrm{La}$ and ca. $108^{\circ}$ for $\mathrm{Sm} ;{ }^{13} \mathrm{E}=\mathrm{N}$ : ca. $112.5^{\circ}$ ). The most convincing argument in favor of the role of the metal $d$ orbitals for enforcing the pyramidal geometry is the relaxation to an essentially planar structure $\left(\mathrm{N}-\mathrm{Sm}-\mathrm{N}=119.4^{\circ}\right)$ when the geometry is reoptimized after removing the $\mathrm{Sm} d$ function from the basis set.

Sm- $N$ bonding. Of the occupied molecular orbitals there are two important sets in the frontier region. The three highest occupied orbitals correspond to the $\mathrm{N}$ lone pair orbitals having $a+e$ symmetry. Below this set lie the three Sm-N $\sigma$ bonding orbitals $(a+e)$ with a shape similar to those previously reported for the trialkyl analogues. ${ }^{13}$ Relative to the latter compounds, the overall metal participation is much reduced, testifying to the expected ionicity increase because of the more electronegative ligand donor atoms. The percent character of various atomic orbitals for the relevant MOs is shown in Table 3. However, some non-negligible metal contribution remains in these Sm-N $\sigma$-bonding MOs and most of it, quite significantly, is of $d$ type. The most important decrease on going from the trialkyl to the triamido compound is that of the $s$ contribution to the $a \sigma$-bonding orbital (from 8.5 to $0.3 \%$ ), but the $d$ contribution is also reduced significantly (e.g. from 15.8 to $7.3 \%$ for the $e$ orbitals).

$<$ Table 3 here $>$ 
A significant, though even smaller contribution from the metal $d$ functions can also be found in the highest three frontier orbitals comprising the $\mathrm{N}$ lone pairs. These are essentially symmetry-adapted linear combinations ( $a$ and $e$ ) of the $\mathrm{N}$ lone pairs and they have the potential of establishing $\pi$-type interactions with the metal $d$ orbitals. A view of these three orbitals is shown in Figure 3. The two e-type orbitals show a small overlap between the $\mathrm{N}$ lone pairs and the metal $d$ orbitals. Because of the pyramidalization, the $a$-type orbital could also establish a $\pi$ type interaction with with the metal $d_{\mathrm{z} 2}$ orbital, but this is very weak and not visible in the contour plot of Figure 3. Whether $\pi$ overlap contributes at all to establish the Sm-N bond distance and strength and other molecular features cannot be unequivocally established. It is certainly not responsible for enforcing the planarity at nitrogen, since this is maintained after reoptimizing the structure in the absence of the $\operatorname{Sm} d$ functions. The substantial lengthening of the Sm-N bond following the removal of the $d$ functions from the metal center cannot be split in relative importance between the $\sigma$ and $\pi$ bonding components. This lengthening demonstrates, however, that the metal $d$ orbitals are indeed important for chemical bonding. If these were purely ionic bonds, this computational experiment should have yielded no structural change. It is interesting to see that the introduction of the $d$ polarization function on the $\mathrm{Si}$ atoms shifts the electron density of the frontier orbitals with a sensible reduction of the $\mathrm{N}$ contribution and a significant contribution from the Si $d$ orbitals. The contribution of all other orbitals (including the Si s and p orbitals) changes by a much smaller extent. This phenomenon results from an increased mixing, when the polarization functions are added, of the $\mathrm{Sm}-\mathrm{N} \sigma$ and $\mathrm{N}$ lone pairs with the N-Si interactions.

$<$ Figure $3>$ 
In order to better assess the bond ionicity issue, we have collected in Table 4 the relevant NBO atomic charges next to the corresponding Mulliken charges for the most significant optimized structures. First and foremost, it is clear that Mulliken and NBO provide a quite different picture for the metal effective charge, which is consistently above +2.5 at the NBO level and around +1 at the Mulliken level. The Mulliken charge of +0.82 for the "real" molecule compares with +0.54 for the previously reported $\mathrm{Sm}\left[\mathrm{CH}\left(\mathrm{SiMe}_{3}\right)_{2}\right]_{2}$. Again, this is in line with the reduced covalent character that is expected for the compound with the more electronegative ligand. Interestingly, the Sm charge jumps from +1.20 to +2.14 after removing the $d$ functions from the Sm center. This result is quite consistent with the MO analysis of Table 3, according to which the Sm-N $\sigma$ bonds are established for the most part by the $\mathrm{Sm} d$ orbitals. Also of interest, however, is the fact that the metal charge increases even at the NBO level upon removal of the $d$ functions, though by a much lower margin. In other words, even the NBO analysis recognizes the covalent participation of the metal $d$ orbitals to the Sm-N bonds.

$<$ Table $4>$

Agostic interactions. The result of the removal of the $d$ orbitals from the Sm atom greatly lengthens the $\mathrm{Sm} \cdots \mathrm{Si}$ and $\mathrm{Sm} \cdots \mathrm{H}$ distances. We must be careful in analyzing this particular structural change, because a lengthening will also be caused indirectly by the Sm-N bond lengthening that was analyzed in the previous section. However, the $\mathrm{Sm} \cdots \mathrm{Si}$ and $\mathrm{Sm} \cdots \mathrm{H}$ distances increase by more than twice as much as the Sm-N distance. A geometrical flattening of the trigonal pyramid affects only the interligand contacts while the internal metal-ligand 
geometry is not altered. However, a significant degree of asymmetry at the level of the Sm-N-Si angles remains. From 103.8 and $132.7^{\circ}$ for the $d(\mathrm{Sm})$ optimized structure, they draw closer to 109.8 and $127.9^{\circ}$ in the $d(\mathrm{Sm})$-free optimization. Once again, no structural change would be expected if the interaction were purely electrostatic. Thus, the presence of the metal $d$ orbitals also has an undeniable beneficial effect for the agostic interactions. On the other hand, a purely covalent interaction that made use exclusively of metal $d$ functions for overlap should completely release the alkyl ligand from the agostic interaction. The two Si-N-Si angles should then become more similar (though a certain asymmetry would still be imposed by the steric interaction between the methyl groups at the base of the pyramid, as can be appreciated from Figure $3(c))$. The question that must now be asked is: why would a significant $\mathrm{Sm}-(\beta-\mathrm{Si}-\mathrm{C})$ interaction remain in the absence of metal $d$ orbitals? We can think of two possible answers to this question, one based on orbital overlap considerations and the other on electrostatic interactions. From the orbital point of view, one unoccupied orbital (the $5 \mathrm{p}_{\mathrm{z}}$ ) still remains unused by the metal and could thus receive electron density from the $\mathrm{Si}-\mathrm{C}$ bonds, although the strength of the interaction would obviously be weaker. Alternatively (or in addition), the negative hyperconjugation argument previously presented by PMEL could account for the remaining interaction. It can be seen from Table 3 that the agostically interacting atoms (e.g. C for the "real" structure and less stable isomer of the model compound; $\mathrm{H}$ for the most stable model isomer) have a slightly greater negative charge relative to the non-interacting atoms of the same type. A similar difference is noted both at the Mulliken and at the NBO level.

Planarity at nitrogen. The planarity of the $\mathrm{N}$ atom in amido derivatives of the transition metals is often interpreted as evidence for the presence of a $\pi \mathrm{M}-\mathrm{N}$ bonding interaction. ${ }^{28}$ The 
observed planar configuration in the structure of $\mathrm{Sm}\left[\mathrm{N}\left(\mathrm{SiMe}_{3}\right)_{2}\right]_{3}$, however, is clearly not attributable to the effect of $\pi$ bonding. The most convincing evidence in favor of this statement comes again from our computational experiment: removing the metal $d$ orbitals does not affect the nitrogen atom planarity. N-Si $\pi$ bonding could also be invoked to explain the $\mathrm{N}$ atom planarity. A result giving a certain support to this hypothesis is the fact that the $\mathrm{Si}-\mathrm{N}$ distance becomes significantly shorter (and closer to the experimental one) when $d$ polarization functions are added to the Si atom. However, this could also be a $\sigma$ effect. The presence of N-Si $\pi$ bonding has been a topic of much discussion. For instance, the planarity of $\mathrm{N}\left(\mathrm{SiMe}_{3}\right)_{3}$ has been attributed to N-Si $\pi$ bonding interactions which involve either the $\mathrm{Si} d$ orbitals $^{29-32}$ or the $\mathrm{SiC} \sigma^{*}$ orbitals (negative hyperconjugation). ${ }^{33}$ It is quite possible, however, that the Sm atom simply finds it energetically preferable to place itself in the plane of the nitrogen for steric reasons (minizing the repulsion with the $\mathrm{SiMe}_{3}$ groups) while $\pi$ interactions may play no role at all. This interpretation is, of course, even more consistent if the $\mathrm{Sm}-\mathrm{N}$ bonds have a predominantly ionic component.

\section{Conclusions}

The present investigation has shown unambiguously that the unusual structural features of $\mathrm{Sm}\left[\mathrm{N}\left(\mathrm{SiMe}_{3}\right)_{2}\right]_{3}$ (and, by extension, also its other lanthanide analogues) may be attributed to the establishment of $\beta$-Si-C agostic interactions between the samarium atom and all three alkyl substituents and to the participation of the metal $d$ orbitals to the Sm-N and Sm- $(\beta-\mathrm{Si}-\mathrm{C})$ bonding. The calculations also suggest that attractive interactions with the $\gamma-\mathrm{C}-\mathrm{H}$ bonds are not present. These interactions are in fact repulsive. The essential features of the $\operatorname{Sm}\left[\mathrm{N}\left(\mathrm{SiMe}_{3}\right)_{2}\right]_{3}$ 
structure can therefore be correctly reproduced by using the simplified $\mathrm{Sm}\left[\mathrm{N}\left(\mathrm{SiH}_{3}\right)\left(\mathrm{SiH}_{2} \mathrm{Me}\right)\right]_{3}$ model system. The addition of polarization functions on the $\mathrm{H}, \mathrm{C}$ and $\mathrm{Si}$ atoms improves the agreement of some bond distances but has a smaller effect than the introduction of the interactive Me group relative to the simpler $\mathrm{Sm}\left[\mathrm{N}\left(\mathrm{SiH}_{3}\right)_{2}\right]_{3}$ model. The removal of the metal $d$ orbitals, on the other hand, induces profound changes. Comparative Mulliken and NBO analyses indicate a significant degree of ionic character in the bonding, including the $\mathrm{Sm}-(\beta-\mathrm{Si}-\mathrm{C})$ agostic interaction. Even by NBO, however, the metal $d$ orbitals are shown to play a significant role in the establishment of the Sm-N interactions. By extrapolation, the metal $d$ orbitals are therefore even more important for bonding in the previously investigated $\mathrm{Sm}\left[\mathrm{CH}\left(\mathrm{SiMe}_{3}\right)_{2}\right]_{3}$ compound, the greater covalency of which is in agreement with trends in the Mulliken charges and in relevant geometrical features (i.e. the greater degree of pyramidalization).

Acknowledgement. This research was sponsored by the Office of Basic Energy Sciences, Division of Chemical Sciences and the Critical Skills Education Program Office of the National Nuclear Security Administration, U.S. Department of Energy under Contract W-7405eng-36 with the University of California. RP is grateful to CINES (Montpellier, France) for granting computer time and the G.T. Seaborg Institute for Transactinium Science for sponsoring stays at Los Alamos National Laboratory (July-August 2001 and July-August 2002). We also thank Dr. Odile Eisenstein for disclosing to us her results (ref. 14) prior to publication.

\section{References}

(1) Fjeldberg, T.; Andersen, R. A. J. Mol. Struct. 1985, 129, 93-105.

(2) Rees, W. S.; Just, O.; VanDerveer, D. S. J. Mater. Chem. 1999, 9, 249-252.

(3) Andersen, R. A.; Templeton, D. H.; Zalkin, A. Inorg. Chem. 1978, 17, 2317-2319. 
(4) Tilley, T. D.; Andersen, R. A.; Zalkin, A. Inorg. Chem. 1984, 23, 2271-2276.

(5) Ghotra, J. S.; Hursthouse, M. B.; Welch, A. J. J. Chem. Soc., Chem. Commun. 1973, 669670.

(6) Herrmann, W. A.; Anwander, R.; Munck, F. C.; Scherer, W.; Dufaud, V.; Huber, N. W.; Artus, G. R. J. Z. Naturforsch. Sect. B 1994, 49, 1789-1797.

(7) Eller, P. G.; Bradley, D. C.; Hursthouse, M. B.; Meek, D. W. Coord. Chem. Rev. 1977, 24, $1-95$.

(8) Stewart, J. L.; Andersen, R. A. Polyhedron 1998, 17, 953-958.

(9) Fjeldberg, T.; Andersen, R. A. J. Mol. Struct. 1985, 128, 49-57.

(10) Ellison, J. J.; Power, P. P.; Shoner, S. C. J. Am. Chem. Soc. 1989, 111, 8044-8046.

(11) Maron, L.; Eisenstein, O. J. Phys. Chem. A 2000, 104, 7140-7143.

(12) Maron, L.; Eisenstein, O. New J. Chem. 2001, 25, 255-258.

(13) Clark, D. L.; Gordon, J. C.; Hay, P. J.; Martin, R. L.; Poli, R. Organometallics, 2002, 21, 5000-5006.

(14) Perrin, L.; Maron, L.; Eisenstein, O.; Lappert, M. F. New J. Chem., 2003, 27, 121-127.

(15) Hitchcock, P. B.; Lappert, M. F.; Smith, R. G.; Bartlett, R. A.; Power, P. P. Chem. Commun. 1988, 1007-1009.

(16) Bradley, D. C.; Ghorta, J. S.; Hart, F. A. J. Chem. Soc. Dalton. Trans. 1973, 1021-1023.

(17) Sheldrick, G. M. SHELXTL, version 5.1; Bruker AXS, Inc.: Madison WI, 1997.

(18) Spek, A. L. Acta Crystallogr., Sect. A: Found. Crystallogr. 1990, 46, C34.

(19) Sheldrick, G. M. SADABS empirical absorption program; University of Göttingen: Göttingen, Germany, 1996.

(20) Becke, A. D. J. Chem. Phys. 1993, 98, 5648-5652.

(21) Dolg, M.; Stoll, H.; Savin, A.; Preuss, H. Theor. Chim. Acta 1989, 75, 173.

(22) Dolg, M.; Stoll, H.; Preuss, H. J. Chem. Phys. 1989, 90, 1730-1734.

(23) Frisch, M. J.; Trucks, G. W.; Schlegel, H. B.; Scuseria, G. E.; Robb, M. A.; Cheeseman, J. R.; Zakrzewski, V. G.; Montgomery, J., J. A.; Stratmann, R. E.; Burant, J. C.; Dapprich, S.; Millam, J. M.; Daniels, A. D.; Kudin, K. N.; Strain, M. C.; Farkas, O.; Tomasi, J.; Barone, V.; Cossi, M.; Cammi, R.; Mennucci, B.; Pomelli, C.; Adamo, C.; Clifford, S.; Ochterski, J.; Petersson, G. A.; Ayala, P. Y.; Cui, Q.; Morokuma, K.; Malick, D. K.; Rabuck, A. D.; Raghavachari, K.; Foresman, J. B.; Cioslowski, J.; Ortiz, J. V.; Baboul, A. G.; Stefanov, B. B.; Liu, G.; Liashenko, A.; Piskorz, P.; Komaromi, I.; Gomperts, R.; Martin, R. L.; Fox, D. J.; Keith, T.; Al-Laham, M. A.; Peng, C. Y.; Nanayakkara, A.; Gonzalez, C.; Challacombe, M.; Gill, P. M. W.; Johnson, B.; Chen, W.; Wong, M. W.; Andres, J. L.; Gonzalez, C.; Head-Gordon, M.; Replogle, E. S.; Pople, J. A. Gaussian 98, Revision A.9; Gaussian, Inc.: Pittsburgh PA, 1998.

(24) Bondi, A. J. Phys. Chem. 1964, 68, 441-451. 
(25) Pyykkö, P. Chem. Rev. 1997, 97, 597-636.

(26) Klooster, W. T.; Brammer, L.; Schaverien, C. J.; Budzelaar, P. H. M. J. Am. Chem. Soc. 1999, 121, 1381-1382.

(27) Reed, A. E.; Curtiss, L. A.; Weinhold, F. Chem. Rev. 1988, 88, 899-926.

(28) Chisholm, M. H.; Clark, D. L. Comments Inorg. Chem. 1987, 6, 23-40.

(29) Hedberg, K. J. Am. Chem Soc. 1955, 77, 6491-6492.

(30) Livant, P.; McKee, M. L.; Worley, S. D. Inorg. Chem. 1983, 22, 895-901.

(31) Beach, D. B.; Jolly, W. L. Inorg. Chem. 1984, 23, 4774-4775.

(32) Rhodes, C. J. J. Chem. Soc., Perkin Trans. II 1992, 235-241.

(33) Reed, A. E.; Schade, C.; Schleyer, P. V.; Kamath, P. V.; Chandrasekhar, J. Chem. Commun. 1988, 67-69. 
Table 1. Crystal Data and Summary of X-ray Data Collection for $\mathrm{Sm}\left[\mathrm{N}\left(\mathrm{SiMe}_{3}\right)_{2}\right]_{3} \cdot 2 \mathrm{C}_{6} \mathrm{H}_{14}$

formula

formula weight

color of cryst

cryst dimens, $\mathrm{mm}$

space group

cell dimens (203(2) K)

$$
a, \AA
$$$$
c, \AA
$$

volume, $\AA 3$

Z

Calcd density, $\mathrm{Mg} / \mathrm{m}^{3}$

abs coeff, $\mathrm{mm}^{-1}$

$F(000)$

radiation type

temperature, $\mathrm{K}$

limits of data collection

total reflcns collected

unique reflcns

weighting scheme
$\mathrm{C}_{30} \mathrm{H}_{82} \mathrm{~N}_{3} \mathrm{Si}_{6} \mathrm{Sm}$

803.91

white

$0.04 \times 0.04 \times 0.12$

$P 3,{ }^{-} 1 c(\# 163)$

$16.4735(7)$

$8.3995(5)$

$1974.04(17)$

2

1.352

1.693

858

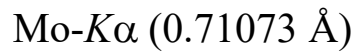

203(2)

$1.40^{\circ} \leq \theta \leq 26.50^{\circ}$

8723

$1365\left(R_{\text {int }}=0.0531\right)$

$w=\left[\sigma^{2}\left(F_{0}^{2}\right)+(A P)^{2}+(B P)\right]^{-1}$,

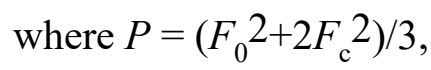

$\mathrm{A}=0.0157, \mathrm{~B}=0$ 
Transmn factors

$R$ indices $(I>2 \sigma(I))$

$R$ indices (all data)

goodness of fit on $F^{2}$

$\max / \mathrm{min}$ peak in final diff map, $\mathrm{e}^{-} / \AA^{3} \quad 0.242 /-0.359$
0.970-0.990

$R=0.0386, R_{w}=0.0860$

$R=0.0427, R_{w}=0.0866$

2.321 
Table 2. Selected Experimental and DFT Optimized Bond Distances $(\AA)$ and Angles $\left({ }^{\circ}\right)$ for $\mathrm{Sm}\left[\mathrm{N}\left(\mathrm{SiR}_{2} \mathrm{Me}\right)\left(\mathrm{SiR}_{3}\right)\right]_{3}$.

\begin{tabular}{|c|c|c|c|c|c|c|}
\hline & \multicolumn{2}{|c|}{$\mathrm{R}=\mathrm{Me}$} & \multicolumn{2}{|c|}{$\mathrm{R}=\mathrm{H}$} & \multicolumn{2}{|c|}{$\mathrm{R}=\mathrm{H}$ (isomer) } \\
\hline & $\exp$ & $6-31 \mathrm{G}$ & $6-31 \mathrm{G}$ & $6-31 \mathrm{G}^{* *}$ & $6-31 \mathrm{G}$ & $6-31 \mathrm{G}($ no $d)$ \\
\hline & \multicolumn{6}{|c|}{ Bond Distances $(\AA)$} \\
\hline Sm-N & $2.284(3)$ & 2.300 & 2.277 & 2.300 & 2.293 & 2.367 \\
\hline $\mathrm{Sm} \cdots \mathrm{Si}$ & $3.2443(8)$ & 3.381 & 3.401 & 3.350 & 3.216 & 3.397 \\
\hline $\mathrm{N}-\mathrm{Si}$ & $1.714(2)$ & 1.788 & 1.783 & 1.726 & 1.773 & 1.765 \\
\hline $\mathrm{N}-\mathrm{Si}$ & $1.714(2)$ & 1.793 & 1.787 & 1.735 & 1.787 & 1.770 \\
\hline $\mathrm{Sm} \cdots \mathrm{C}$ & $3.003(4)$ & 3.190 & 3.28 & 3.177 & & \\
\hline $\mathrm{Si}-\mathrm{CH}_{3}(\cdots \mathrm{Sm})$ & $1.879(4)$ & 1.944 & 1.936 & 1.915 & & \\
\hline Si- $\mathrm{CH}_{3}$ (other) & $1.865(3)$ & 1.920 & & & & \\
\hline \multirow[t]{2}{*}{$\mathrm{Sm} \cdots \mathrm{H}(\mathrm{C})$} & $2.80(4)$ & 2.93 & 3.04 & 3.00 & & \\
\hline & $2.85(4)$ & 3.10 & 3.18 & 3.02 & & \\
\hline \multirow{2}{*}{$\mathrm{C}-\mathrm{H}(\cdots \mathrm{Sm})$} & $1.04(4)$ & 1.101 & 1.101 & 1.101 & & \\
\hline & $0.94(4)$ & 1.100 & 1.099 & 1.099 & & \\
\hline C-H(other) & $0.90(4)$ & 1.097 & 1.096 & 1.096 & & \\
\hline $\mathrm{Sm} \cdots \mathrm{H}(\mathrm{Si})$ & - & & & & 2.716 & 2.975 \\
\hline $\mathrm{Si}-\mathrm{H}(\cdots \mathrm{Sm})$ & - & & & & 1.545 & 1.542 \\
\hline \multirow{3}{*}{ Si-H(other) } & - & & & & 1.506 & 1.508 \\
\hline & & & & & 1.506 & \\
\hline & \multicolumn{6}{|c|}{ Bond Angles $\left({ }^{\circ}\right)$} \\
\hline $\mathrm{N}-\mathrm{Sm}-\mathrm{N}$ & $115.52(2)$ & 116.3 & 112.5 & 112.5 & 114.1 & 119.4 \\
\hline $\mathrm{Sm}-\mathrm{N}-\mathrm{Si}$ & 107.6(1) & 111.0 & 113.2 & 111.9 & 103.8 & 109.8 \\
\hline Sm-N-Si & $126.4(1)$ & 126.3 & 125.3 & 122.5 & 132.7 & 127.9 \\
\hline Si-N-Si' & $125.4(2)$ & 122.5 & 121.4 & 125.6 & 123.3 & 122.3 \\
\hline $\mathrm{N}-\mathrm{Si}-\mathrm{CH}_{3}(\cdots \mathrm{Sm})$ & 107.6(1) & 106.5 & 107.6 & 107.6 & & \\
\hline \multirow[t]{2}{*}{ N-Si-R } & $113.8(1)$ & 114.2 & 114.2 & 114.6 & & \\
\hline & 113.3(1) & 115.2 & 113.1 & 114.0 & & \\
\hline \multirow[t]{2}{*}{$\mathrm{Si}-\mathrm{C}-\mathrm{H}(\cdots \mathrm{Sm})$} & $113(2)$ & 113.1 & 112.6 & 113.8 & & \\
\hline & $109(2)$ & 113.3 & 112.6 & 113.4 & & \\
\hline Si-C-H(other) & $111(2)$ & 107.7 & 108.6 & 108.6 & & \\
\hline N-Si-H( $\cdots \mathrm{Sm})$ & & & & & 57.8 & 61.1 \\
\hline \multirow[t]{3}{*}{ N-Si-H(other) } & & & & & 124.3 & 126.1 \\
\hline & & & & & 127.1 & 126.4 \\
\hline & \multicolumn{6}{|c|}{ Dihedral angles $\left(^{\circ}\right)$} \\
\hline Sm-N-Si- & $3.8(2)$ & 6.9 & 6.5 & 2.1 & & \\
\hline $\mathrm{C}(\cdots \mathrm{Sm})$ & & & & & & \\
\hline $\mathrm{Sm} \cdots \mathrm{Si}-\mathrm{C}-\mathrm{H}$ & - & 68.4 & 67.1 & 63.8 & & \\
\hline & - & -58.6 & -58.3 & -62.8 & & \\
\hline $\begin{array}{l}\text { Sm-N-Si- } \\
\mathrm{H}(\cdots \mathrm{Sm})\end{array}$ & & & & & 2.9 & 0.9 \\
\hline
\end{tabular}


Table 3. Percent Mulliken contribution of various atomic orbitals in the relevant MOs of compounds $\mathrm{Sm}\left[\mathrm{N}(\mathrm{SiMe})_{2}\right]_{3}$ and $\mathrm{Sm}\left[\mathrm{N}\left(\mathrm{SiH}_{3}\right)\left(\mathrm{SiH}_{2} \mathrm{Me}\right)\right]_{3}$ in comparison with compound $\mathrm{Sm}\left[\mathrm{CH}\left(\mathrm{SiMe}_{3}\right)_{2}\right]_{3}{ }^{13}$.

\begin{tabular}{|c|c|c|c|c|c|c|c|c|c|c|c|c|c|c|}
\hline \multirow[t]{3}{*}{$\mathrm{AO}$} & \multirow{2}{*}{\multicolumn{2}{|c|}{$\begin{array}{c}\mathrm{Sm}\left[\mathrm{CH}\left(\mathrm{SiMe}_{3}\right)_{2}\right]_{3} \\
(6-31 \mathrm{G})\end{array}$}} & \multirow{2}{*}{\multicolumn{4}{|c|}{$\begin{array}{c}\mathrm{Sm}\left[\mathrm{N}\left(\mathrm{SiMe}_{3}\right)_{2}\right]_{3} \\
(6-31 \mathrm{G})\end{array}$}} & \multicolumn{8}{|c|}{$\mathrm{Sm}\left[\mathrm{N}\left(\mathrm{SiH}_{3}\right)\left(\mathrm{SiH}_{2} \mathrm{Me}\right)\right]_{3}$} \\
\hline & & & & & & & \multicolumn{4}{|c|}{$(6-31 G)$} & \multicolumn{4}{|c|}{$\left(6-31 \mathrm{G}^{* *}\right)$} \\
\hline & $a(\sigma)$ & $a(\sigma)$ & $a(\sigma)$ & $e(\sigma)$ & $e(\mathrm{lp})$ & $a(\mathrm{lp})$ & $a(\sigma)$ & $e(\mathrm{lp})$ & $a(\mathrm{lp})$ & $e(\sigma)$ & $a(\sigma)$ & $e(\sigma)$ & $e(\mathrm{lp})$ & $a(\mathrm{lp})$ \\
\hline E & -0.213 & -0.206 & -0.257 & -0.250 & -0.214 & -0.205 & -0.283 & -0.280 & -0.236 & -0.225 & -0.291 & -0.287 & -0.251 & -0.240 \\
\hline $\operatorname{Sm}(s)$ & 8.5 & 0.1 & 0.3 & 0.0 & 0.0 & 0.5 & 3.0 & 0.0 & 0.0 & 0.0 & 3.8 & 0.0 & 0.0 & 0.0 \\
\hline $\operatorname{Sm}(p)$ & 0.0 & 0.1 & 0.0 & 0.0 & 0.0 & 0.5 & 0.2 & 0.9 & 0.5 & 0.8 & 0.5 & 1.4 & 1.0 & 0.5 \\
\hline $\operatorname{Sm}(d)$ & 1.8 & 15.8 & 2.1 & 7.3 & 5.0 & 1.0 & 2.3 & 8.5 & 7.3 & 1.6 & 2.8 & 9.0 & 7.4 & 0.8 \\
\hline $\mathrm{N}(\text { tot })^{\mathrm{a}}$ & 59.7 & 60.2 & 44.5 & 48.6 & 63.4 & 68.8 & 55.9 & 57.0 & 67.6 & 74.2 & 47.9 & 47.0 & 60.9 & 69.3 \\
\hline $\operatorname{Si}(d)^{b}$ & - & - & - & - & - & - & - & - & - & - & 4.1 & 3.4 & 5.5 & 4.7 \\
\hline
\end{tabular}

${ }^{\mathrm{a}} \alpha$-Carbon atom for the $\mathrm{Sm}\left[\mathrm{CH}\left(\mathrm{SiMe}_{3}\right)_{2}\right]_{3}$ compound; total for all three $\mathrm{N}$ atoms and for all $\mathrm{N}$ functions. ${ }^{\mathrm{b}}$ Total for all six Si atoms (only d functions).

Please check this ordering: it is different than for all other calculations, while the numbers retain the same trends. 
Table 4. Mulliken and NBO charges on relevant atoms for $\mathrm{Sm}\left[\mathrm{N}\left(\mathrm{SiR}_{2} \mathrm{Me}\right)\left(\mathrm{SiR}_{3}\right)\right]_{3}$.

\begin{tabular}{|c|c|c|c|c|c|c|c|c|c|c|}
\hline & \multirow{2}{*}{\multicolumn{2}{|c|}{$\begin{array}{l}\mathrm{R}=\mathrm{Me} \\
6-31 \mathrm{G}\end{array}$}} & \multicolumn{4}{|c|}{$\mathrm{R}=\mathrm{H}$} & \multicolumn{4}{|c|}{$\mathrm{R}=\mathrm{H}$ (isomer) } \\
\hline & & & \multicolumn{2}{|c|}{$6-31 \mathrm{G}$} & \multicolumn{2}{|c|}{$6-31 \mathrm{G}^{* *}$} & \multicolumn{2}{|c|}{$6-31 \mathrm{G}$} & \multicolumn{2}{|c|}{$6-31 \mathrm{G}($ no $d)$} \\
\hline & Mulliken & NBO & Mulliken & NBO & Mulliken & NBO & Mulliken & NBO & Mulliken & NBO \\
\hline Sm & 0.82 & 2.65 & 1.17 & 2.61 & 1.10 & 2.61 & 1.20 & 2.61 & 2.14 & 2.81 \\
\hline $\mathrm{N}$ & -1.30 & -1.86 & -1.25 & -1.80 & -1.44 & -1.90 & -1.23 & -1.79 & -1.44 & -1.82 \\
\hline $\mathrm{Si}$ & 1.32 & 1.84 & 0.96 & 1.24 & 1.16 & 1.42 & 0.95 & 1.26 & 0.94 & 1.26 \\
\hline $\mathrm{Si}^{\prime}$ & 1.32 & 1.85 & 0.80 & 0.96 & 1.02 & 1.15 & 0.85 & 0.97 & 0.81 & 0.98 \\
\hline $\mathrm{C}_{\text {agost }}$ & -0.85 & -1.26 & -0.82 & -1.22 & -0.85 & -1.25 & & & & \\
\hline $\mathrm{C}_{\text {other }}$ & -0.74 & -1.21 & - & - & - & - & -0.76 & -1.18 & -0.78 & -1.18 \\
\hline $\mathrm{H}_{\text {agost }}$ & & & & & & & -0.20 & -0.25 & -0.23 & -0.25 \\
\hline $\mathrm{H}_{\text {other }}{ }^{\mathrm{a}}$ & - & - & -0.14 & -0.17 & -0.17 & -0.21 & -0.14 & -0.17 & -0.14 & -0.17 \\
\hline
\end{tabular}

${ }^{\mathrm{a}} \mathrm{SiH}_{3}$ group only. 


\section{Captions for Figures}

Figure 1. A thermal ellipsoid view of the molecular structure of compound $\left.\mathrm{Sm}\left[\mathrm{N}\left(\mathrm{SiMe}_{3}\right)_{2}\right)\right]_{3}$. Ellipsoids are drawn at the $50 \%$ probability level.

Figure 2. Views of the B3LYP optimized structures for $\operatorname{Sm}\left[\mathrm{N}\left(\mathrm{SiR}_{2} \mathrm{Me}\right)\left(\mathrm{SiR}_{3}\right)\right]_{3}$. (a) $\mathrm{R}=$ Me; (b) $\mathrm{R}=\mathrm{H}$; (c) more stable isomer of the $\mathrm{R}=\mathrm{H}$ molecule.

Figure 3. View of the three highest occupied MOs for the $\left.\operatorname{Sm}\left[\mathrm{N}\left(\mathrm{SiMe}_{3}\right)_{2}\right)\right]_{3}$ molecule: (a) $a$ orbital; (b) $e_{1}$ orbitals; (c) $e_{2}$ orbital. 
Figure 1

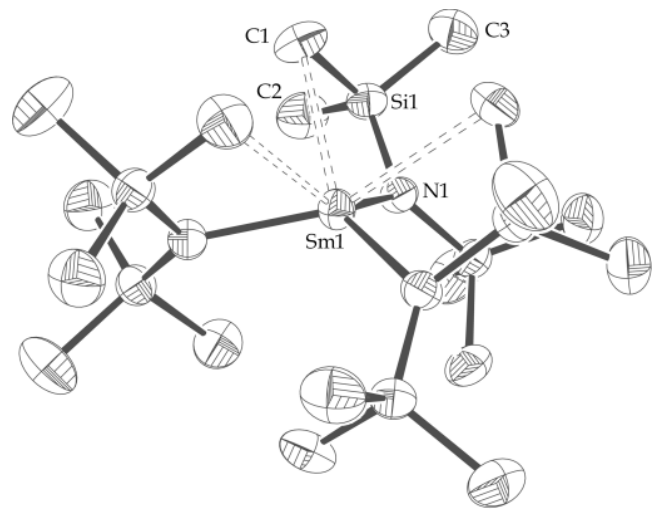


31

Figure 2
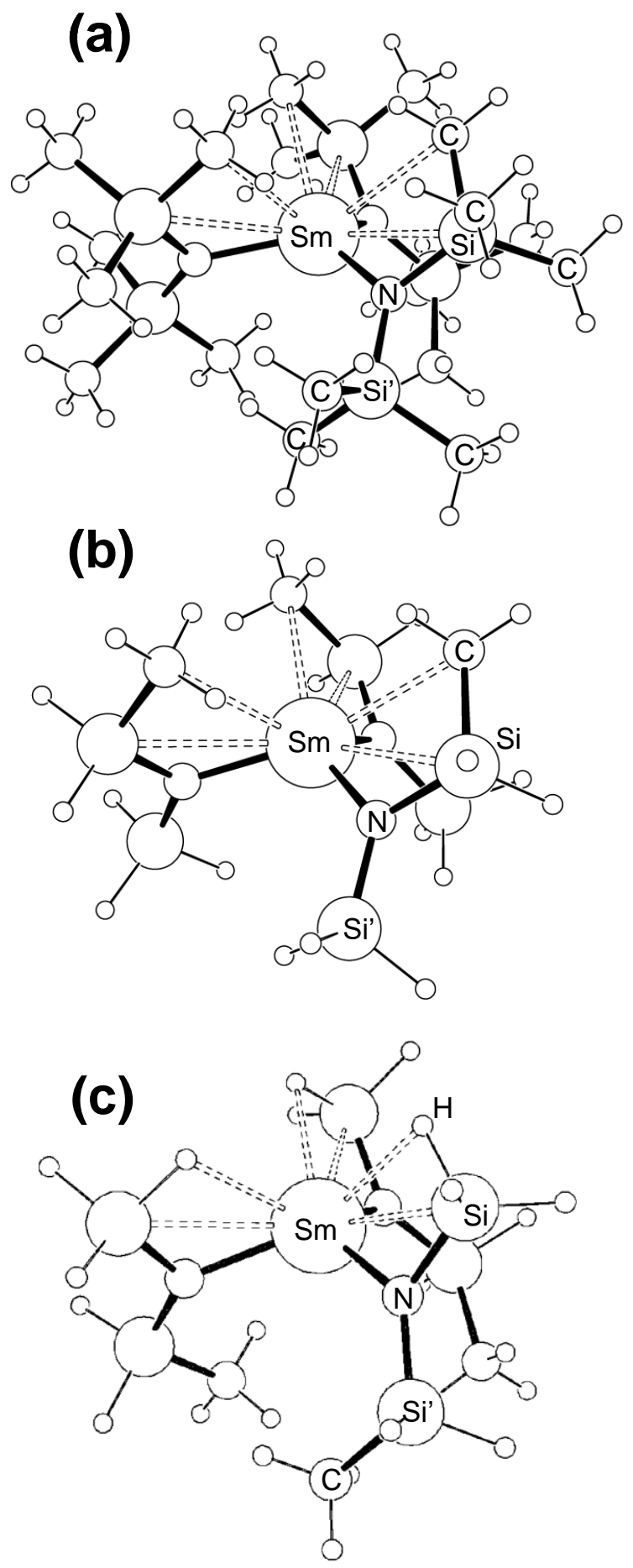
Figure 3

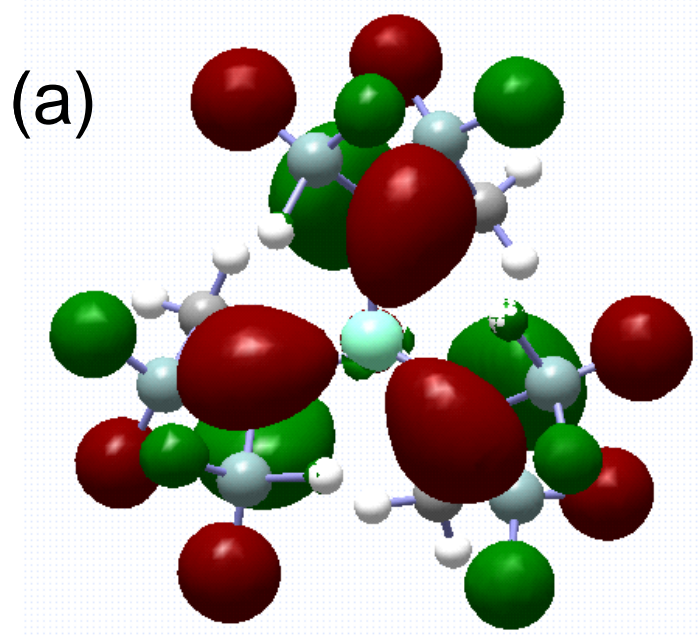

(b)
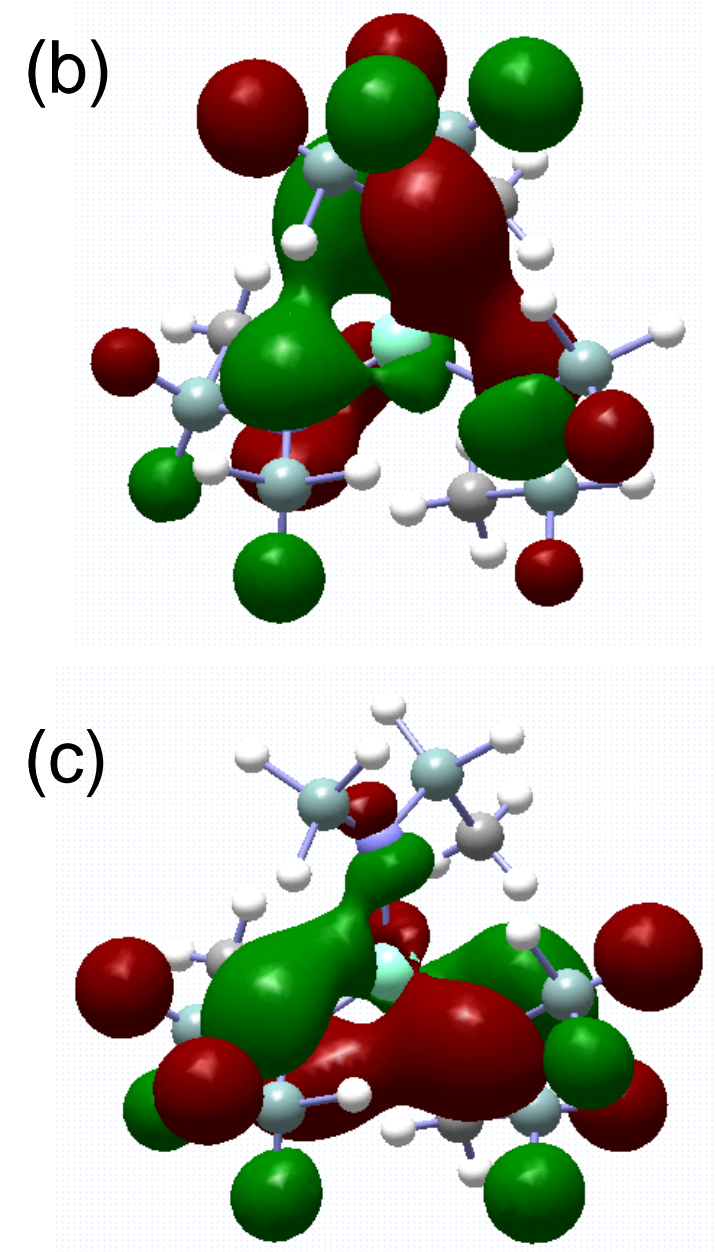
Scheme 1

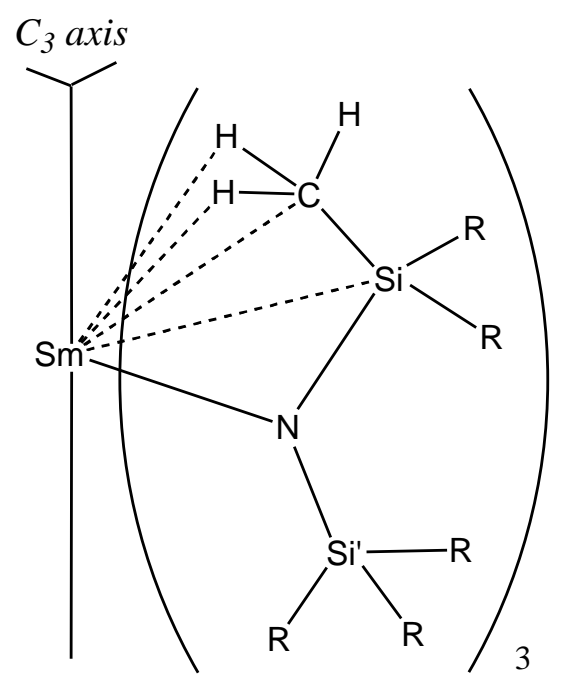

